\title{
Reply to comment by J. J. Barsugli et al. on "When will Lake Mead go dry?"
}

\author{
Tim P. Barnett ${ }^{1}$ and David W. Pierce ${ }^{1}$ \\ Received 18 May 2009; revised 13 July 2009; accepted 22 July 2009; published 17 September 2009.
}

Citation: Barnett, T. P., and D. W. Pierce (2009), Reply to comment by J. J. Barsugli et al. on "When will Lake Mead go dry?," Water Resour. Res., 45, W09602, doi:10.1029/2009WR008219.

[1] The comment by Barsugli et al. [2009] has three main thrusts. The first deals with the water budget model we employed. In follow-up work, now published by Barnett and Pierce [2009], we revised the water budget model accounting for all the points they raise plus a few more. The results of this new work strongly support our original conclusion of upcoming, serious problems with the Colorado River water supply. A second main question deals with our assumption of 1 million acre-feet (MAF) per year $(1 \mathrm{MAF}=$ $1.2335 \times 10^{9} \mathrm{~m}^{3}$ )of overdrafting of Lake Mead and whether this is reasonable and representative of the combined MeadPowell system. We show that lakes Mead and Powell combined have been losing an average of nearly $2 \mathrm{MAF} / \mathrm{a}$ over the last 11 years, so our $1 \mathrm{MAF} / \mathrm{a}$ assumption is well supported by the data. Finally, they wonder about our suggestion that we begin to address the coming water problem now rather than waiting, concluding that the risks to the water supply on the Colorado are serious but that there is a window of opportunity to allow developing management strategies to address these issues. We agree that the risks are serious. But we argue that the U.S. Bureau of Reclamation's current plan as outlined in the interim guidelines, which is to call a meeting of interested parties when Lake Mead reaches a $1025 \mathrm{ft}(312.4 \mathrm{~m})$ elevation, is tantamount to waiting until a water crisis is upon us to act. That would be both foolhardy and irresponsible; we believe the stakeholders in the Colorado River system deserve better.

[2] In "When will Lake Mead go dry?" [Barnett and Pierce, 2008] (hereinafter referred to as BP2008), we used a simplified water balance model to examine the effects of anthropogenic climate change on the Colorado River system. In particular, we calculated the likelihood of active storage in Lake Mead becoming depleted ("running dry"), assuming no preventative action were taken, a caveat plainly stated but ignored in criticisms of BP2008. The motivation for doing this work was a United States Bureau of Reclamation (BOR) final environmental impact statement (EIS) published in late 2007, detailing guidelines for managing the main Colorado River reservoirs for the next 20 years and showing increasing water deliveries from the reservoirs for the next 50 years [Bureau of Reclamation, 2007]. Remarkably, this document took no account of anthropogenic climate change, despite the long time horizon of the report and numerous works suggesting that climate change would reduce runoff to the river (see

\footnotetext{
${ }^{1}$ Division of Climate, Atmospheric Sciences, and Physical Oceanography, Scripps Institution of Oceanography, La Jolla, California, USA.
}

Copyright 2009 by the American Geophysical Union. 0043-1397/09/2009WR008219\$09.00 eight examples in Table 1 of Barnett and Pierce [2009] (hereinafter referred to as BP2009)). BP2008 found that if nothing were done, there was a substantial chance of Lake Mead's storage becoming exhausted, with " $50 \%$ chance by" dates ranging from 2021 to 2048, depending on the particular assumptions made as to inflow to the system, delivery cuts, and the effect of climate change [Barnett and Pierce, 2008, Table 1]. There was no hint nor suggestion in the 2007 EIS that the water supply from the Colorado River faced any such risks.

[3] In their comment, Barsugli et al. [2009] (hereinafter referred to as BNRPH) criticize a number of aspects of BP2008, which we address below. However, we note that Barsugli et al. [2009, paragraph ?] conclude that the "risks to the water supply on the Colorado are serious" and that they hope their comment "serves to put the [BP2008] analysis on a stronger footing." We would be doing a disservice to the people of the southwestern United States if we did not begin by clearly pointing out our mutual agreement on this point, which stands in stark contrast to the 2007 EIS, which indicated no problems with the water supply.

[4] After the reference by BP2008 was published, we received a substantial amount of feedback on that work, including some well-reasoned criticisms of our methodology. To address these criticisms, we modified the water budget model to include more effects, including explicitly retaining all the inflows and losses below Lees Ferry, lake evaporation that depends on the surface area of the reservoirs, and a treatment of bank storage that is identical to that used in the BOR's full model of the Colorado River (issues noted by $\mathrm{BNRPH}$ ). The results from this improved version of the water budget model are described by BP2009.

[5] All of the points raised by BNRPH are addressed in the work by BP2009, where we continue to find that humaninduced climate change, if it occurs as predicted, will seriously impair the reliability of the Colorado River water supply. However, we would like to take this opportunity to comment on the issues discussed by BNRPH.

[6] First, Barsugli et al. [2009, paragraph 1] state that "the most serious of these [questionable assumptions by BP2008] is the neglect of over 800,000 acre-feet of intervening flows" between Lake Mead and Lake Powell. However, it needs to be understood that we compensated for this by omitting the $\sim 900,000$ acre-feet $(1$ acre-foot $=$ $1234 \mathrm{~m}^{3}$ ) of annual losses below Hoover Dam. In a water balance model, only the net of inflows and losses matter, so the exclusion of compensating inflows and losses is irrelevant. This criticism is correct in the sense that the various intervening inflows and losses between Lees Ferry and the Imperial Dam do not exactly balance (they are a net positive 
Table 1. Active Storage in Lake Mead, Lake Powell, and Their Sum and the End of October of the Indicated Year, Along With the Change From the Previous Year $^{\mathrm{a}}$

\begin{tabular}{|c|c|c|c|c|c|c|}
\hline Year $^{\text {b }}$ & Mead Storage & $\begin{array}{l}\text { Change From } \\
\text { Previous Year }\end{array}$ & Powell Storage & $\begin{array}{l}\text { Change From } \\
\text { Previous Year }\end{array}$ & $\begin{array}{l}\text { Mead-Powell } \\
\text { Storage }\end{array}$ & $\begin{array}{l}\text { Change From } \\
\text { Previous Year }\end{array}$ \\
\hline 1997 & 24,343 & $\mathrm{NA}^{\mathrm{f}}$ & 22,554 & $N A^{f}$ & 46,897 & $N A^{f}$ \\
\hline 1998 & 25,278 & +935 & 22,198 & -356 & 47,476 & +579 \\
\hline 1999 & 24,717 & -561 & 22,534 & +336 & 47,251 & -225 \\
\hline 2000 & 22,435 & $-2,282$ & 20,753 & $-1,781$ & 43,188 & $-4,063$ \\
\hline 2001 & 19,882 & $-2,553$ & 18,802 & $-1,951$ & 38,684 & $-4,504$ \\
\hline 2002 & 17,032 & $-2,850$ & 14,270 & $-4,532$ & 31,302 & $-7,382$ \\
\hline 2003 & 15,517 & $-1,515$ & 11,935 & $-2,335$ & 27,452 & $-3,850$ \\
\hline 2004 & 14,094 & $-1,423$ & 9,148 & $-2,787$ & 23,242 & $-4,210$ \\
\hline 2005 & 15,078 & +984 & 12,016 & $+2,868$ & 27,094 & $+3,852$ \\
\hline 2006 & 13,964 & $-1,114$ & 12,526 & +510 & 26,490 & -604 \\
\hline 2007 & 12,510 & $-1,454$ & 11,930 & -596 & 24,440 & $-2,050$ \\
\hline 2008 & 12,213 & -297 & 14,172 & $+2,242$ & 26,385 & $+1,945$ \\
\hline
\end{tabular}

${ }^{\mathrm{a}}$ Units are kilo acre-feet (KAF).

${ }^{\mathrm{b}}$ All measurements are from the end of October of each year.

${ }^{\mathrm{c}}$ The average of this column is $-1102 \mathrm{KAF} / \mathrm{a}$.

${ }^{\mathrm{d}}$ The average of this column is $-762 \mathrm{KAF} / \mathrm{a}$.

'The average of this column is $-1865 \mathrm{KAF} / \mathrm{a}$.

${ }^{\mathrm{f}} \mathrm{NA}$ means the values were not available.

input of about $0.45 \mathrm{MAF} / \mathrm{a}$ of water into the system), so we included all these terms explicitly in the work by BP2009. This value represents about $3 \%$ of the mainstream flow. We note that large year-to-year fluctuations in Colorado River flow give substantial sampling errors, so the mean river flow can only be estimated to within about $3 \%$.

[7] The second point Barsugli et al. [2009, paragraph 3] raise is that "the critical reason for BP2008's alarming results is the assumption that the system is currently operating at a long-term deficit of 1.0 MAF/a." As BNRPH correctly note, this was an assumption, not a deduction based on historic flows of the Colorado River. BP2008 presented other dry-by dates based on different assumptions, including ones based on historic Colorado River flows. These later dry-by dates [Barnett and Pierce, 2008, Table 1] and the associated caveats were largely ignored by critics of BP2008. However, BNRPH's point is worth exploring. Why did we assume a net inflow of $-1 \mathrm{MAF} / \mathrm{a}$ (using BP2008's terminology) for our computation of the 2021 dry-by date? And is such an assumption unreasonable?

[8] We assumed a net inflow of $-1 \mathrm{MAF} / \mathrm{a}$ because that is what Lake Mead has been experiencing during the past decade. The values are shown in Table 1, taken from the BOR's "24 month" operating reports [e.g., Bureau of Reclamation, 2008]. BP2008 used the last 10 years, but we have extended this to include results from the most recent year, which were unavailable to BP2008. The average loss in Lake Mead storage over this period was 1.1 MAF/a. Barsugli et al. [2009, paragraph 21] note that "the reference by BP2008 to the Lake Mead water balance being in a deficit of $1 \mathrm{MAF}$ is not adequate justification for assuming a similar deficit in the Mead-Powell system, as other factors ... are relevant and have tended to amplify the effects at Mead compared to Powell." Table 1 also shows results for Lake Powell and the Mead-Powell system, the latter of which has lost an average of $1.87 \mathrm{MAF} / \mathrm{a}$ over this period, nearly twice the $1 \mathrm{MAF} / \mathrm{a}$ assumed by BP2008. The maximum 2007 EIS delivery cuts of 0.6 MAF/a could have been imposed during this entire time and the average loss would still have been 1.27 MAF/a. We therefore disagree that assuming a net loss of $1 \mathrm{MAF} / \mathrm{a}$ is unreasonable, particularly when viewed in the context of the numerous sets of assumptions explored by BP2008. We also note that the neglect of the $0.45 \mathrm{MAF} / \mathrm{a}$ of intervening inflow discussed above has no effect on the results of this case, which used an assumed net inflow equal to the observed value.

[9] The other point BNRPH address regarding whether assuming a deficit of $1 \mathrm{MAF} / \mathrm{a}$ is reasonable concerns the long-term mean flow of the Colorado River. Both BP2008 and BP2009 used a 20th-century value of about $15 \mathrm{MAF} / \mathrm{a}$ but pointed out that tree ring records do not support this, instead showing uniformly lower values for the long-term flow. Barsugli et al. [2009, paragraph 20] note that "there is no clear agreement in the scientific literature about the magnitude of these two effects" (drying from anthropogenic climate change and the relative wetness of the 20th century). However, different estimates of anthropogenic runoff reduction are of the same sign and are remarkably similar in magnitude [Barnett and Pierce, 2009, Table 1]. Similarly, all of the tree ring reconstructions that we are aware of show that the 20th century was quite unusually wet (statistics are given by BP2009). So although both estimates have uncertainty, they both point to less water availability. Given the degree of agreement between estimates of the anthropogenic effect and also of tree ring estimates of mean river flow, we suggest it is past time to begin incorporating this information into long-term planning of the Colorado River, as contingencies or scenarios if nothing else. We specifically point out that in addition to neglecting anthropogenic climate change, the BOR in its 2007 EIS assumes that the very wet period of the 20th century will be replicated in the 21st century, an assumption at odds with the tree ring data.

[10] One conclusion from BP2008 was that the existing shortage guidelines (i.e., water delivery cuts) outlined in the 2007 EIS are insufficient to make much difference to any of the dry-by dates. This is an important point, since one of the criticisms leveled at BP2008 has been that the 2007 EIS delivery cuts are big enough to preserve the reliability of the system. In the work by BP2008, and also in the work by BP2009 where we used the improved water balance model, we found this was not true. Barsugli et al. [2009, paragraph 7] wrote that "if the existing shortage guidelines are taken into 
account, the 'doomsday clock' is set back by another year or two" and "gains [from the delivery cuts] are modest." Our interpretation is that BNRPH's results support our point that the currently agreed upon shortage guidelines are insufficient to make much of a difference to the reliability of the system in the face of anthropogenic climate change.

[11] Further addressing this subject, Barsugli et al. [2009, paragraph 19] say that "the interim guidelines allow for the development of more stringent reductions in deliveries should Lake Mead drop below 1025 feet $(312.4 \mathrm{~m})$ above sea level, opening up the prospect of a powerful management tool [for mitigating drought]." However, all the interim guidelines say is that the appropriate parties will be "reconsulted" in that eventuality.

[12] We do not believe that it is widely appreciated among the millions of people served by the Colorado River that the current emergency plan in the event of low water levels is, put baldly, to call a meeting. As explicitly stated by BP2008, we are not claiming, nor do we believe, that nothing would be done should this dire turn of events come to pass. But we also think that real, detailed, and concrete planning for this contingency is needed.

[13] In their discussion section, BNRPH touch on a number of issues. The first issue raised is that "the image of the reservoir ... 'running dry' is a powerful one. It suggests a finite natural resource that has been used up for good" [Barsugli et al., 2009, paragraph 18]. Later, they point out that the reservoir running dry is not the same as the river running dry and that the river would continue to flow nonetheless. Barnett and Pierce [2008, paragraph 43] specifically said that "in the future we can count on some flow in the Colorado, albeit $10-30 \%$ less in (say) 50 years than the current rate." However, we disagree with the implicit suggestion that exhausting the reservoir storage in some year is not highly relevant, even if the reservoir later recovers. Tens of millions of people and millions of acres of farmland depend on this water supply. Exhaustion of reservoir storage in such an important system, even for 1 year, would be a disaster to the people who rely on that supply for their daily livelihoods. This is true even when the reservoir has a chance of restoring some of the storage in later years. If nothing else, exhausting the reservoir storage would put the region at the mercy of year-to-year vagaries of precipitation, a situation that the system was constructed exactly to avoid.

[14] BNRPH close with a discussion of the time frame, noting that precipitative action and hastily made policies carry risk. Our concern is that this appears to be the path laid out by the interim guidelines. If Lake Mead elevation did fall to 1025 feet $(312.4 \mathrm{~m})$ above sea level, triggering the interim guideline's call for a meeting, storage in Mead would be only 1.5 MAF above the level currently needed to maintain uninterrupted water supplies to Las Vegas and surrounding communities. Table 1 shows that this could leave an uncomfortably short margin of safety, perhaps only a few years, before Lake Mead's level could fall below Las Vegas' current intake, depending on exactly how Lake Powell were handled in such a contingency. Such a situation may well lead to the sort of hasty, ineffective, and inefficient actions that BNRPH justly criticize.
[15] It is exactly because we agree with BNRPH's point that we need considered plans, rather than hasty reactions associated with reconsulting in a crisis, that we call for work on this issue to begin now. It takes years to hammer out agreements on western water issues. By starting now to include climate change scenarios in long-range planning of the Colorado River supply, we can devise plans to preserve the reliability of the system before we reach a crisis situation.

[16] We also agree with BNRPH that future demand is an important factor and deserves more examination. The U.S. Census Bureau estimates that the population in the lower basin area served by the Colorado River will grow by approximately 10 million people by 2030 . These people will require 1-2 MAF/a of water, which is not likely to come from a fully allocated Colorado River system. Where will that water come from, and what impact might it have on the important agricultural industry of the region? We believe that the entire picture of water supply, demand, and population increases need to be considered as a whole, rather than treating the reservoir operation as an isolated entity.

[17] The problems the Colorado River water supply faces are not intractable, they are not insurmountable, and they are not hopeless. However, they may become so if we do not admit the problem, address the issues, and implement solutions.

[18] In closing, we would like to thank BNRPH for their interest in our work, the professional tone of their comment, and the effort they have spent to help bring the science of climate change to bear on the important issue of Colorado River water supplies. We feel that this exchange, plus the work by BP2009, bring the coming crisis on the Colorado River into sharper focus. Millions of people in the west, including the authors, have benefited from the foresight, long-range vision, and careful engineering of our forbearers in building one of the most amazing water storage and delivery systems in the world. We owe it to future generations to leave them a system that protects their livelihoods as effectively as it has protected ours.

\section{References}

Barnett, T. P., and D. W. Pierce (2008), When will Lake Mead go dry?, Water Resour. Res., 44, W03201, doi:10.1029/2007WR006704.

Barnett, T. P., and D. W. Pierce (2009), Sustainable water deliveries from the Colorado River in a changing climate, Proc. Natl. Acad. Sci. U. S. A., 106, 7334-7338, doi:10.1073/pnas.0812762106.

Barsugli, J. J., K. Nowak, B. Rajagopalan, J. R. Prarie, and B. Harding (2009), Comment on "When will Lake Mead go dry?" by T. P. Barnett and D. W. Pierce, Water Resour. Res., 45, W09601, doi:10.1029/ 2008 WR007627.

Bureau of Reclamation (2007), Colorado River interim guidelines for lower basin shortages and coordinated operations for Lake Powell and Lake Mead: Final environmental impact statement, U. S. Dep. of the Inter., Boulder City, Nev. (Available at http://www.usbr.gov/lc/region/programs/ strategies/FEIS/index.html)

Bureau of Reclamation (2008), Operation Plan for Colorado River System Reservoirs. Lower Colorado Region, Boulder Canyon Oper. Off., River Oper. Group, U. S. Dep. of the Inter., Boulder City, Nev.

T. P. Barnett and D. W. Pierce, Division of Climate, Atmospheric Sciences, and Physical Oceanography, Scripps Institution of Oceanography, La Jolla, CA 92093-0224, USA. (timdotbarnett@ucsd.edu) 